\title{
RIPPLE EFFECT AND REGIONAL HOUSE PRICES DYNAMICS IN CHINA
}

\author{
Chi-Chuan LEE a, Chien-Chiang LEE ${ }^{\text {b,* }}{ }^{*}$, Shu-Hen CHIANG ${ }^{\text {c }}$ \\ a School of Management, Beijing Normal University Zhuhai, Zhuhai, China \\ ${ }^{b}$ Department of Finance, National Sun Yat-sen University, Kaohsiung, 804, Taiwan \\ ${ }^{c}$ Department of Finance, Chung Yuan Christian University, Chung Li, Taiwan
}

Received 11 November 2014; accepted 17 August 2015

\begin{abstract}
This paper examines the stationarity properties, the long-run equilibrium and the leadlag relationship among the regional house prices in China from December 2000 to July 2013. Unlike traditional unit-root tests, the panel seemingly unrelated regressions augmented Dickey-Fuller (SURADF) unit-root test reveals that the regional house prices in China are a mixture of I(0) and I(1) processes. There is concrete evidence in favor of the hypothesis of a long-run equilibrium relationship among all regions, except for Shanghai region, and supporting the price diffusion or ripple effect among these Chinese cities. Finally, we determine that these regional house prices exhibit uni-directional causalities running from Beijing, Chongqing, and Shenzhen to Guangzhou and Tianjin, respectively.
\end{abstract}

KEYWORDS: Regional house prices; Ripple effect; Panel SURADF test; Half-life; China

\section{INTRODUCTION}

The price diffusion or ripple effect refers to the phenomenon whereby price shocks in one area have a permanent or a transitory effect on the house prices of other metropolitan areas - that is the so-called price diffusion or ripple effect. Many studies have discussed what causes such ripple effect in housing markets. For example, Meen (1999) points out that price shocks ripple out across the economy is caused by equity transfer, spatial arbitrage, migration, and spatial pattern in the determinants of house prices. If the ripple effect is valid, there should be long-run relativities between the regions. As such, the government can identify the original shock of local housing prices and intervene with the real estate market in the source region, rather than that all regions (Chiang 2014). Therefore, the intervention policies could improve efficiency by using the right cure for the disease. Consequently, an essential issue to government is to investigate the behaviour of regional house prices.

The real estate market in China has experienced a wide range of fundamental changes ever since the completion of the urban housing system

\footnotetext{
* Corresponding author. E-mail: cclee@cm.nsysu.edu.tw
}

reforms in 1998. One of the main characteristics is the establishment of marketization through removal of the welfare housing system. Since then, China's real estate market has achieved rapid development along with economic growth. On the one hand, the rapid economic growth has created strong housing demand in the typical housing market. On the other hand, the real estate market has become the most powerful engine for stimulating the Chinese economy (Yang et al. 2013). Therefore, fluctuations in housing prices would crucially influence the overall economy from the macroeconomic perspective. An interesting question to Chinese government then arises as to how one should think about understanding the price transmissions across regions and maintaining a stable the relationship between housing prices and the economy (Hui, Yue 2006).

In addition, the housing price appreciation in China is much greater than that experienced in US during the housing boom from 1995 to 2006 (Wu et al. 2012). As stated by Guo and Huang (2010) China's real estate price can be enlarged the appreciation by various factors, i.e., housing privatization reform, acceleration of urbanization, high saving rate, the lack of diversified investment 
instruments, and speculative investment demand. The surging house prices appreciation have raised concerns of the behavior of regional house prices. This is particularly the case in some large cities, such as Beijing, Guangzhou, Shanghai, and Shenzhen, where the house price has been skyrocketing. In this regard, the housing price diffusion or ripple effect across regions has become increasingly important for investors, economists and policymakers to formulate an appropriate investment strategies and optimal stable policies.

Even though there is a large body of literature that investigates the issue of ripple effect, there is still no conclusive results among them. Many earlier works have already performed investigations of interregional relationship between different regional house prices by using some econometric tests, such as Engle and Granger (1987) or Johansen (1988) cointegration tests. The conclusions drawn from these relative studies are diverse. One part of them tend to support the ripple effect (e.g., MacDonald, Taylor 1993; Alexander, Barrow 1994; Chien 2010; Chen et al. 2011), while another other do not (e.g., Ashworth, Parker 1997).

Another strand of contemporary literature examines the stationarity properties of the ratio between each regional price and the national house price by examining unit root tests. In the presence of ripple effect, the regional house price ratio is stationary (see, for example, Meen 1999; Cook 2005; Canarella et al. 2012; Balcilar et al. 2013). Though these numerous studies are sufficient in the past, but there are still imperfections in accordance with previous finding. For example, while examining the spatial diffusions among regional house prices, ripple effects are generally considered as a unit root problem suffering from the lack of the long-run equilibrium and the lead-lag relationship among regional house prices in different areas. Furthermore, previous studies use the limited length of time-series data to investigate stationarity properties of regional house prices. To solve the problem of small samples, the panel data approach has recently been applied to analyze related issues (Holmes 2007; Holmes, Grimes 2008; Lee, Chien 2011; Lean, Smyth 2013).

To fill up the gap in the literature, this paper aims to focus on the stationarity properties and the long-run relationship of China's regional house prices with monthly data from December 2000 to July 2013. For one, the stationarity properties are examined by applying the panel seemingly unrelated regressions augmented Dickey-Fuller (Panel SURADF) test which developed by Breuer et al.
(2001). It offers an advantage to account for possible cross-sectional effects and to identify which prices within the panel are non-stationary. Secondly, once the stationarity is confirmed, the speed of mean reversion can be captured through measuring the half-lives and the corresponding confidence intervals. Thirdly, following the framework of cointegration method with those prices which are identified as integrated of order one I(1), we then investigate the existence of cointegration relationship (MacDonald, Taylor 1993; Chen et al. 2011). Finally, the weak exogeneity test is applied to investigate the causal relationship in order to verify the ripple effects among different regional house prices.

The rest of the paper is organized as follows. Section 2 briefly reviews the relevant literature concerning the ripple effect. Section 3 discusses the econometric methods. Section 4 introduces the data source and discusses the empirical results. Finally, Section 5 reviews our conclusions, while also outlining some of the implications based on the empirical findings from this extensive research.

\section{LITERATURE REVIEW}

The behavior of regional house prices has drawn much attention to researchers since many local housing markets have undergone major changes in boom and bust cycles around the world (Canarella et al. 2012). Some studies have focused on the relationship between house prices and their fundamentals. See, for example, Reilly and Witt (1994), Malpezzi (1999), Hui and Yue (2006), Gallin (2006), Fraser et al. (2008) and Lean and Smyth (2014), to mentioned a few. Some additional works have studied the spillover of housing price changes within neighbouring areas, such as Clapp et al. (1995), Dolde and Tirtiroglu (1997), Chen et al. (2011) as well as Kuethe and Pede (2011).

Recently, there has been an extensive academic literature devoted to an examination of ripple effects among regional house prices. As defined by Liao et al. (2015), the ripple effect should comprise two essentially different kinds. The first one states that a pronounced shock entering a region has significant influence in the economy. The other one describes a price diffusion mechanism among neighboring markets. From a theoretical point of view, house prices from different regions do not move together, i.e., the market is regionalized. This is because house prices depend on variations in local housing market supply and demand factors which can differ substantially between regions 
due to differences in regional economic and demographic environments (Shi et al. 2009; Canarella et al. 2012; Balcilar et al. 2013). However, Meen (1996, 1999) provides some different theories including equity transfer between regions (i.e., relocating), arbitrage between regions (i.e., trading), external migration to the region, and spatial effects of exogenous shocks, which are commonly suggested as an explanation for the ripple effect. Therefore, the housing prices in all regions eventually move together over the long run.

The literature on ripple effects in house prices is quite extensive. Some studies investigate the causalities among different regional house prices by employing Engle and Granger (1987) or Johansen (1988) procedures. Using the cointegration technique, MacDonald and Taylor (1993) and Alexander and Barrow (1994) support the long-run interregional relationship among the UK regional house prices. Gupta and Miller (2012) suggest similar results for the US housing markets. Differently, Drake (1995) applies the Kalman filter approach for estimating time-varying parameter to investigate the convergence of regional house prices in the UK and finds little evidence of a relation between regional house prices. Ashworth and Parker (1997) also report no significant ripple effect in the UK by applying the error-correction model (ECM) and the Lagrange multiplier (LM) test.

Another line of research casts the ripple effect as a univariate unit root problem, ever since the pioneering work of Meen (1999). Adopting the augmented Dickey-Fuller (ADF) unit root test, Meen (1999) provides little evidence that the ratio of regional house prices to the national house prices is stationary supporting the absence of ripple effect in the UK. Cook (2003) applies momentum threshold autoregressive (MTAR) models to address the possible asymmetries in the adjustment towards the long-run equilibrium between different regional house prices in the UK. The results support the stationarity of regional house price ratios.

Relying on a joint application of two powerful unit root tests, i.e., the DF-GLS test (Elliott et al. 1996) and KPSS test (Kwiatkowski et al. 1992), Cook (2005) confirms the existence of ripple effect in the UK. Chien (2010) and Canarella et al. (2012) further employ the minimum Lagrange multiplier (LM) unit root test with two structural breaks, proposed by Lee and Strazicich (2003), to investigate the presence of ripple effect. Evidence shows that ripple effect hypothesis is supported in the Taiwan and US economies. Balcilar et al. (2013) also reach similar results in South Afri- can house prices based on Baysian and non-linear unit root analysis.

It is now extensively supported that conventional univariate unit root tests not only fail to consider the information across regions, but are also restricted in regard to the small sample problem, thereby leading to less efficient estimations. In this regard, panel data approach provides more powerful test and estimates. Holmes and Grimes (2008) investigate the ripple effect using panel unit root testing with principal component analysis in the UK. The long-run convergence of regional house prices is found in their analysis. Lean and Smyth (2013) adopt panel LM unit toot test with one and two structural breaks to examine the ripple effect in the Malaysian housing market. Their empirical results suggest that ripple effect is found from the most developed states to the less developed states.

The relevant China's studies are still limited. As far as the China's house prices are concerned, little attention has been paid to the examination of the dynamic linkage among regional house price indices in different cities. Huang et al. (2010a) provide evidence on the existence of the ripple effect in Chinese nine cities by using the technique of cointegration, error correction model, vector error correction model, impulse response analysis, and variance decomposition. Huang et al. (2010b) further extends the empirical data to nineteen cities and analyze the ripple effect based on two-stage procedure of non-parametric testing and business cycle dating techniques. They find evidence supporting ripple effect in China. With regard to recent development in panel data, Zhang and Morley (2014) show that the ripple effect is stemmed from Shanghai, Guangzhou, and Beijing and its effect seems to weaken as the distance from one of the core cities increases.

To sum up, all of the aforementioned works that deal with ripple effect rely on either examining cointegration relationship between different regional house prices or investigating the stationarity properties of the house price ratio. Our paper takes a different route and offers novel insights on the behavior for regional house prices. A broader class of testing procedures is used not only to detect the stationarity properties, but also to examine the long-run equilibrium, and the lead-lag relationship among regional house prices in China.

\section{METHODOLOGY}

The empirical testing procedure consists of four steps. In the first step, we implement the SURADF panel unit-root test to ascertain the stationarity 
properties of regional house prices. By doing so, the house prices among each regional market are classified into $\mathrm{I}(1)$ and $\mathrm{I}(0)$ series - according to the results of the SURADF test. Second, to provide a complete analysis of the short-run adjustments and the mean reversion process, we estimate the half-lives and the associated confidence intervals once the stationary behavior for regional house prices is confirmed. Third, we investigate the relationships between the regional house prices of I(1) using the Johansen cointegration procedures. Finally, from the perspective of housing market management and economic or financial policies, it is important to confirm causalities between different regional housing activities. Thus, we employ the weak exogeneity test to investigate the causality relationships and examine the ripple effects among different regional house prices.

At the beginning of our analyses, it has been widely recognized by researchers that panel data approach is an appropriate way to increase power when testing for a unit root. One of the most notable works is as in Breuer et al. (2001, 2002), who showed that the recent methodological refinements to the Levin et al. (2002, LLC) test fail to fully address the "all-or-nothing" nature of the test. The rejection of LLC test indicates that at least one panel member is stationary, with no information of individual behavior.

This dilemma motivated Breuer et al. (2001, 2002) to develop a panel unit-root test based on the augmented Dickey-Fuller (ADF; Dickey-Fuller 1979) regression estimation in a seemingly unrelated regressions (SUR) framework and then tested for an individual unit root within the panel members. Several advantages are worth mentioning. First, the information of variance-covariance matrix is used in these multivariate tests to avoid the unrealistic assumption of cross-sectional independence made in the panel tests. Second, by exploiting the information from the error covariance and allowing for an autoregressive process, the multivariate ADF-type unit-root tests produce more efficient estimators than the simplified single-equation models do. Third, the estimation tests also allow for heterogeneity in the lag structure among individual members of the panel. That is, the lag order of the augmented test varies among the individuals, and the autoregressive parameter also differs for every cross section. Finally, the panel SURADF unit-root test is capable of detecting how many and which members of the panel contain a unit root (Lee et al. 2013).

The unit-root test of the panel SURADF for $N$ regions and $T$ time periods is based on the system of $\mathrm{ADF}$ equations, which can be represented as:

$$
\begin{aligned}
& \Delta Y_{1, t}=\alpha_{1}+\beta_{1} Y_{1, t-1}+\gamma t+\sum_{j=1}^{k 1} \phi_{1, j} \Delta Y_{1, t-j}+\varepsilon_{1, t} \\
& t=1,2, \ldots ., T \\
& \Delta Y_{2, t}=\alpha_{2}+\beta_{2} Y_{2, t-1}+\gamma t+\sum_{j=1}^{k 2} \phi_{2, j} \Delta Y_{2, t-j}+\varepsilon_{2, t} \\
& t=1,2, \ldots ., T \\
& \vdots \\
& \Delta Y_{N, t}=\alpha_{N}+\beta_{N} Y_{N, t-1}+\gamma t+\sum_{j=1}^{k N} \phi_{N, j} \Delta Y_{N, t-j}+\varepsilon_{N, t} \\
& t=1,2, \ldots ., T,
\end{aligned}
$$

where: $Y$ denotes real regional house prices, and $\varepsilon_{i, t}(i=1,2, \ldots, N)$ is an error term. Coefficient $\alpha_{i}$ is the heterogeneous constant term, $\beta_{i}=\rho_{i}-1$, where $\rho_{i}$ is the autoregressive coefficient for the $i^{\text {th }}$ cross-sectional member of the series, and $t$ denotes the deterministic time trend.

Equation (1) tests the null hypothesis of a unit root against trend stationarity. The model allows for heterogeneous fixed effects, heterogeneous trend effects, and heterogeneous lags for each cross-sectional unit in the panel. The flexibility to test for a unit root within each cross-sectional unit is especially beneficial for applied work, where mixed stationary and non-stationary series are likely. This system is estimated by the SUR procedure, and we test the $\mathrm{N}$ null $\left(H_{o}^{i}\right)$ and alternative hypotheses $\left(H_{A}^{i}\right)$ individually as:

$$
\begin{aligned}
& H_{0}^{1}: \beta_{1}=0 ; H_{A}^{1}: \beta_{1}<0 \\
& H_{0}^{2}: \beta_{2}=0 ; H_{A}^{2}: \beta_{2}<0 \\
& \vdots \\
& H_{0}^{N}: \beta_{N}=0 ; H_{A}^{N}: \beta_{N}<0,
\end{aligned}
$$

with the test statistics being computed from SUR estimates of system (1), while the critical values are generated by Monte Carlo simulations.

The unit-root tests are even more importantly uninformative as to the speed of mean reversion in regional house prices. Alternatively, the "halflife" of deviation - defined as the number of periods required for a unit shock to dissipate by one half - measures the degree of mean reversion and the speed of adjustment back towards the longrun equilibrium. To examine this measure, suppose that the deviations of the house price series $Y_{i, t}$ from its long-run value $Y_{i, 0}$ follow an $\operatorname{AR}(1)$ process:

$$
Y_{i, t}-Y_{i, 0}=\alpha\left(Y_{i, t-1}-Y_{i, 0}\right)+u_{i, t},
$$

where: $u$ is white noise. The half-life deviation $h$ is defined as the horizon at which the percent- 
age deviation from the long-run equilibrium is one half - that is:

$$
\alpha^{h}=\frac{1}{2} \Rightarrow h=\frac{\ln (1 / 2)}{\ln (\alpha)} .
$$

A conventional 95\% confidence interval associated with the above half-life statistic based on normal distributions can thus be defined as:

$$
\hat{h} \pm 1.96 \hat{\sigma}_{\hat{\alpha}}\left(\frac{\ln (0.5)}{\hat{\alpha}}[\ln (\hat{\alpha})]^{-2}\right) .
$$

Here, $\hat{\sigma}_{\hat{\alpha}}$ is an estimate of the standard deviation of $\alpha$. Since $h$ cannot be negative, we impose a lower bound of zero ${ }^{1}$.

\section{EMPIRICAL RESULTS}

\subsection{Alternative unit-root tests and the degree of mean reversion}

This empirical analysis consists of the monthly housing price indices from six Chinese cities, i.e., Beijing $(P E K)$, Chongqing $(C K G)$, Guangzhou $(C A N)$, Shanghai (SHA), Shenzhen $(S Z X)$, and Tianjin (TSN), which are obtained from the China Real Estate Index System (CREIS), as indicators of house prices in different cities ${ }^{2}$. These six cities have the largest population expansion, employment opportunities and economic growth in China and are a magnet for more efficient investment and businesses. For example, the Beijing and Shanghai market play an important role as a price leader and should be watched for policy control, while Shenzhen is the first special economic zone in China, which makes is significantly distinct from other cities. The sample data cover the time period from December 2000 to July $2013^{3}$. Figure 1 presents the geographical location of the China regions. Chongqing is the seat of the interior area, while the other cities are located in the Eastern region. All price indexes are expressed in natural logarithms and are deflated with a base point of 1,000 in Beijing in December 2000. Figure 2 includes the time-series plots of the six house price indices included in our model and the box plots summarizing the distribution of a set of data. The box plot is composed using few primary elements: the edges of the box are the first and third quartiles; the median and mean is depicted using a line and a symbol in the

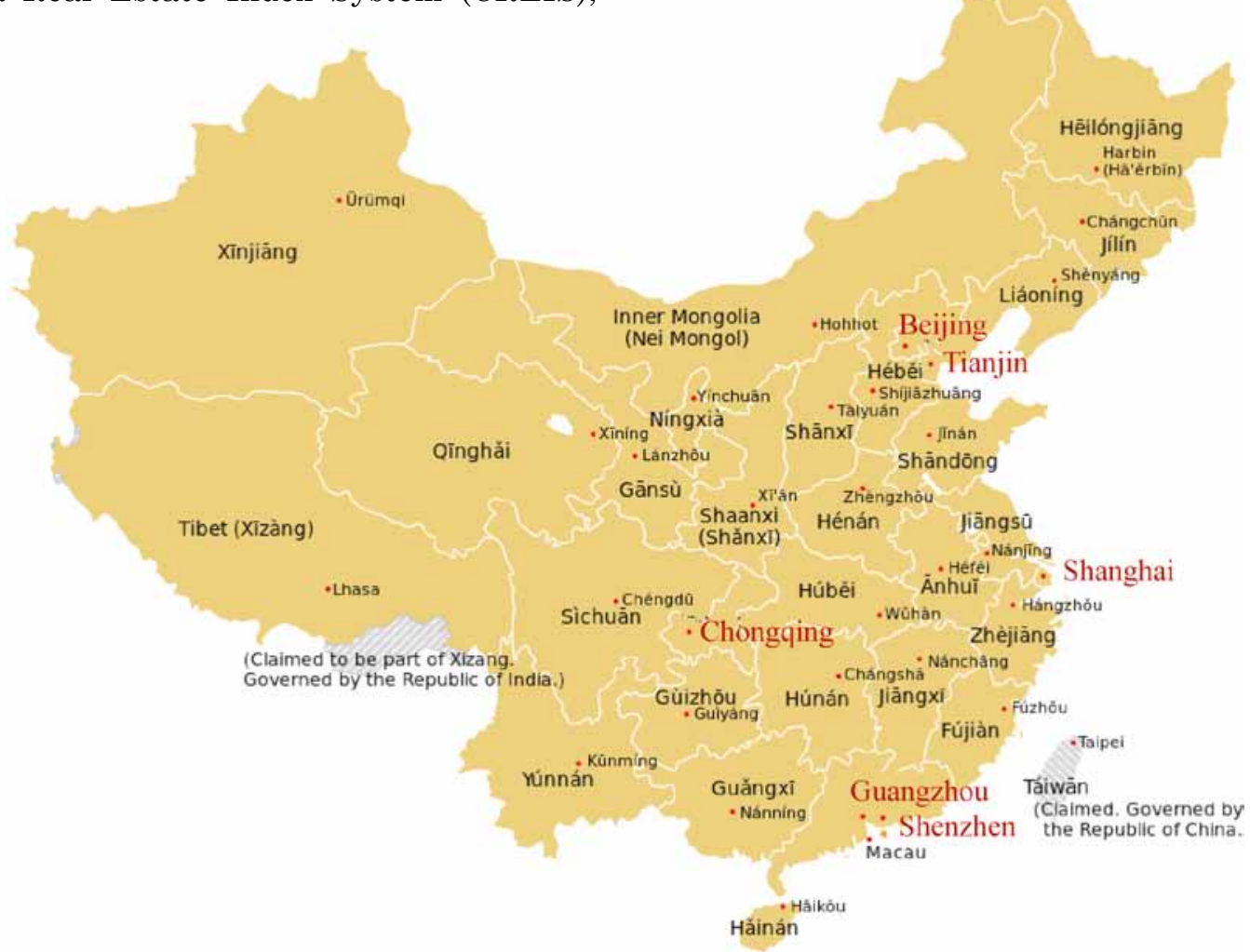

Fig. 1. Provincial map in China (source: http://en.wikipedia.org/wiki/Wikipedia)

\footnotetext{
${ }^{1}$ See Rossi (2005) for more details.

2 Although the city-level housing price indices prices are widely used in housing research, applications to Chinese cities are limited by data availability in CRIES.

${ }^{3}$ CRIES provides information of some additional cities (Chengdu, Hangzhou, Nanning, Qingdao, Suzhou, Wuhan) but the available data for certain reasons (the longer data coverage and the relative importance) are not as useful as the sample with existing 6 major cities.
} 


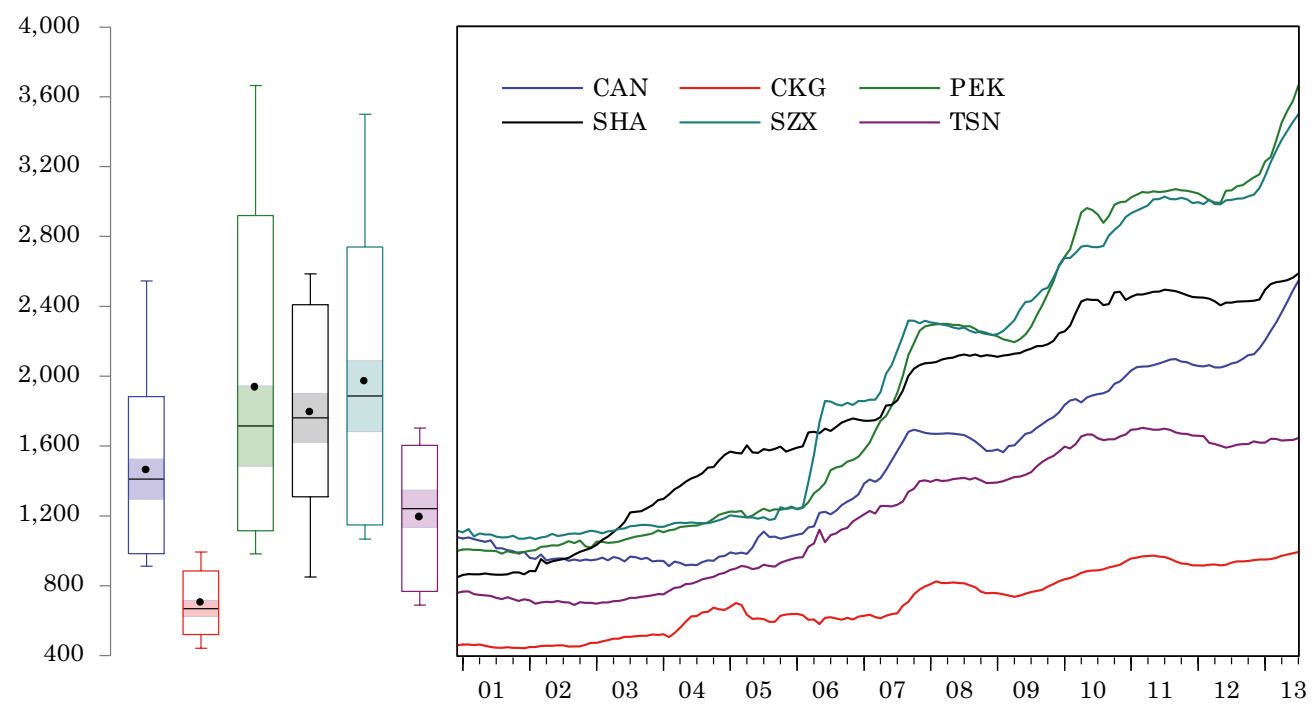

Fig. 2. Plots of regional house prices

box, respectively; the staple is drawn at the last data point. It is apparent that all of the variables show rising trends, suggesting that, at least initially, we need to include a linear trend in our model.

Empirical research studies in finance have long presented a great deal of attention on the timeseries properties of financial asset prices (e.g., Narayan, Smyth 2007). As a benchmark, the empirical work begins by testing for the presence of a unit root in regional house prices using a battery of traditional univariate unit-root tests, including ADF (Dickey, Fuller 1979), DF-GLS (Elliott et al. 1996), PP (Phillips, Perron 1988), KPSS (Kwiatkowski et al. 1992), and NP (Ng, Perron 2001) unit-root tests. The estimation method adopted in this research is based on the modified Schwarz information criterion of Liu et al. (1997) in the ADF, DF-GLS and the NP tests for selecting the optimal lag length, and the kernel-based criteria of Newey and West (1994) in the PP and the KPSS tests for choosing the bandwidth. Table 1 reports the results of these univariate unit-root tests with a drift and a deterministic time trend, showing that all variables are non-stationary at the $5 \%$ significance level.

For the purpose of providing an analysis of sensitivity and robustness, the procedure used here includes a broad array of panel unit-root tests, such as the test of Levin et al. (2002, LCC), Breitung (2000), Im et al. (2003, IPS), the Fisher-ADF and Fisher-PP tests proposed by Maddala and $\mathrm{Wu}$ (1999), and Hadri (2000). Table 2 summarizes the results of the panel unit-root tests, showing that the statistics significantly confirm that all series are non-stationary at the 5\% significance level, that is, all variables are I(1).

With respect to the issue of heterogeneity, the behaviour of regional house prices in the economy may be varied across regions, and thus the traditional panel unit roots applied herein may present misleading inferences. To provide a more accurate inference regarding the number of unit roots or stationary cross-sectional elements, we utilize the Breuer et al. $(2001,2002)$ test with the null of non-stationarity being tested individually

Table 1. Univariate unit root tests results of regional house prices

\begin{tabular}{llllll}
\hline Region & ADF & DF-GLS & PP & KPSS & NP( MZ $\left.Z_{\alpha}^{G L S}\right)$ \\
\hline Beijing & $-2.254(1)$ & $-1.334(1)$ & $-2.258(8)$ & $0.164(10) * *$ & -3.734 \\
Chongqing & $-1.801(0)$ & $-1.724(0)$ & $-2.725(7)$ & $0.076(9)$ & -5.819 \\
Guangzhou & $-2.687(1)$ & $-0.621(1)$ & $-2.659(7)$ & $0.177(10) * *$ & -1.088 \\
Shanghai & $-0.166(0)$ & $-0.005(0)$ & $-0.509(6)$ & $0.327(10) * *$ & 0.034 \\
Shenzhen & $-2.506(1)$ & $-1.733(1)$ & $-2.272(6)$ & $0.150(10) * *$ & -6.170 \\
Tianjin & $-1.165(2)$ & $-0.918(2)$ & $-1.292(8)$ & $0.203(10) * *$ & -2.067 \\
\hline
\end{tabular}

Note: ** indicates significance at the $5 \%$ level. DF-GLS and $M Z_{\alpha}^{G L S}$ are unit root tests proposed by Elliott et al. (1996) and $\mathrm{Ng}$ and Perron (2001), respectively. The numbers in parentheses are the lag order in the ADF and DF-GLS tests. The lag parameters are selected on the basis of SC. The truncation lags are for the Newey-West correction of the PP and $M Z_{\alpha}^{G L S}$ tests in parentheses. The null hypothesis of the KPSS test examines for $\mathrm{I}(0)$, while the null of the remaining four tests examines for I(1). 
Table 2. Panel unit root and stationary tests for regional house prices

\begin{tabular}{ll}
\hline Method & Statistic \\
\hline LLC & -0.020 \\
Breitung & 0.286 \\
IPS & 1.298 \\
Fisher-ADF & 7.552 \\
Fisher-PP & 9.159 \\
Hadri & $7.445 * *$ \\
\hline
\end{tabular}

Notes: LLC and IPS represent the panel unit root tests of Levin et al. (2002) and Im et al. (2003), respectively. Fisher-ADF and Fisher-PP represent the Maddala and Wu (1999) Fisher-ADF and Fisher-PP panel unit root tests, respectively. ** indicates statistical significance at $5 \%$ level. Probabilities for Fisher-type tests are computed by using an asymptotic Chi-square distribution. All other tests assume asymptotic normality. The LLC, Breitung, IPS, Fisher-ADF, and Fisher-PP tests examine the null hypothesis of non-stationarity, while Hadri tests the stationary null hypothesis.

in the SUR grid. Table 3 provides the results of the panel SURADF unit-root tests and the critical values for different regional house prices. As the SURADF test has non-standard distributions, the critical values have to be generated through Monte Carlo simulations based on 10,000 replications by using the lag and covariance structure from the panel of regional house prices. Our results reveal that these regional house prices have a mixture of $\mathrm{I}(0)$ and $\mathrm{I}(1)$ processes. The null hypothesis of nonstationarity is rejected for Shanghai, indicating that house prices in Shanghai are trend-stationary, i.e., I(0). The price level should then return to its long-run trend path over time. Thus, it should possibly predict future movements based on past behaviour, providing useful information for analysts. By contrast, house price shocks stemming from the other five regions in China to regional housing markets are likely permanent.

Table 3. Panel SURADF tests and critical values for regional house prices

\begin{tabular}{lllll}
\hline Region panel label & SURADF & \multicolumn{3}{l}{ Critical values } \\
\cline { 3 - 5 } & & 0.01 & 0.05 & 0.1 \\
\hline Beijing (PEK) & -0.026 & -3.557 & -3.000 & -2.714 \\
Chongqing (CKG) & -1.150 & -3.480 & -2.922 & -2.632 \\
Guangzhou (CAN) & 1.079 & -3.663 & -3.078 & -2.789 \\
Shanghai (SHA) & $-4.589 *$ & -3.604 & -3.038 & -2.774 \\
Shenzhen (SZX) & -0.570 & -3.699 & -3.135 & -2.818 \\
Tianjin (TSN) & -1.564 & -3.692 & -3.166 & -2.862 \\
\hline
\end{tabular}

Notes: $* * *$, and $* * *$ indicate significance at the $10 \%, 5 \%$, and $1 \%$ levels, respectively. Critical values are calculated using the Monte Carlo simulation with 10,000 draws, tailored to the present sample size (For details of this simulation, see Breuer et al. 2001).
Even though the same unit-root hypothesis is rejected, deviations from the long-run equilibrium are still persistent to varying degrees. In other words, the unit-root tests alone are not sufficient to justify the adjustment dynamics of a long-run equilibrium for regional house prices and are uninformative as to the degree of mean reversion. To get a clearer picture, we construct half-lives and associated confidence intervals to investigate the persistence of deviations in regional house prices. Table 4 provides the half-lives and their confidence intervals, in which the half-lives in Shanghai are approximately 2.75 years.

Table 4. Estimated half-lives and confidence intervals

\begin{tabular}{llll}
\hline $\begin{array}{l}\text { Region panel } \\
\text { label }\end{array}$ & $\beta$ & $\begin{array}{l}\text { Estimated } \\
\text { half-life } \\
\text { (monthly) }\end{array}$ & $\begin{array}{l}\text { Confidence } \\
\text { interval } \\
\text { at 95\% level }\end{array}$ \\
\hline $\begin{array}{l}\text { Shanghai } \\
\text { (SHA) }\end{array}$ & -0.0208 & 33.03 & {$[0,87.69]$} \\
\hline
\end{tabular}

Note: Rossi (2005) proposed the method of estimation of the confidence intervals for half-lives.

\subsection{Evidence of ripple effects}

Having ascertained that Beijing, Chongqing, Guangzhou, Shenzhen, and Tianjin in a panel sense are non-stationary I(1) processes, we further conduct Johansen's (1988) multivariate maximum likelihood cointegration test to investigate the long-run relationship among these regional house prices, along with Johansen and Juselius' (1990) cointegrated vector coefficient significance test. Before proceeding to the Johansen's (1988) multivariate maximum likelihood cointegration test, the appropriate number of lag lengths which should be high enough to ensure that the errors are approximately white noise, but small enough to allow estimation has to be selected in advance. In this regard, the optimal lag lengths are chosen by using several selection criteria, such as the final prediction error (FPE) method, Akaike's information criterion (AIC), Schwarz information criterion (SC), and Hannan-Quinn criterion (HQ). According to the results of Table 5, the optimum lag length is determined to be two. Using this lag length, the Ljung-Box (1978) portmanteau autocorrelation test is then employed to detect for a residual serial correlation up to the specified order. Table 6 presents the summary of portmanteau test statistics and shows that the null hypothesis of no serial correlation up to lag $h$ cannot be rejected at the $5 \%$ level. This result confirms that residuals of the VAR model do not exhibit serial correlation, which justifies the use of the optimum lag periods. 
Table 5. VAR lag order selection

\begin{tabular}{lllll}
\hline $\begin{array}{l}\text { Lag } \\
\text { intervals }\end{array}$ & FPE & AIC & SC & HQ \\
\hline 1 & $6.80 \mathrm{E}-19$ & -27.64 & -27.03 & -27.39 \\
2 & $1.97 \mathrm{E}-19^{\mathrm{a}}$ & $-28.89^{\mathrm{a}}$ & $-27.76^{\mathrm{a}}$ & $-28.43^{\mathrm{a}}$ \\
3 & $2.32 \mathrm{E}-19$ & -28.72 & -27.09 & -28.06 \\
4 & $2.27 \mathrm{E}-19$ & -28.75 & -26.60 & -27.88 \\
\hline
\end{tabular}

Table 6. VAR model residuals' portmanteau test for autocorrelations

\begin{tabular}{llll}
\hline Model & $\begin{array}{l}\text { Number } \\
\text { of Lagged } \\
\text { periods }\end{array}$ & $\mathrm{LM}(2)$ & $\mathrm{LM}(4)$ \\
\hline PEK, CKG, CAN, & 2 & 28.829 & 23.395 \\
SZX, TSN, trend & & {$[0.271]$} & {$[0.555]$} \\
\hline
\end{tabular}

Given the results, it is appropriate to examine whether there is a cointegration relationship among the four regional house prices. Consider the VAR(p) model, the testing hypothesis is formulated as the restriction for the reduced rank of $\Pi=H_{0}(r)=\Pi=\alpha \beta^{\prime}$. Table 7 reports the test statistics along with corresponding $5 \%$ finite sample critical values from testing for the number of cointegrating vectors, based on the maximum eigenvalue (MAX) and the trace (TRACE) of the stochastic matrix in the multivariate framework. Both tests suggest the existence of one cointegrating vector $(r=1)$ driving the series with common stochastic trends in the data, indicating that there is a stable long-run equilibrium relationship among the five regional house prices in China.

Table 7. Johansen's multivariate cointegration tests

\begin{tabular}{lllll}
\hline Model & \multicolumn{3}{c}{$H_{04}$} & Trace \\
& \multicolumn{1}{l}{ Statistic } & $\begin{array}{l}\text { Critical } \\
\text { value }\end{array}$ & Statistic & $\begin{array}{l}\text { Critical } \\
\text { value }\end{array}$ \\
\cline { 2 - 5 }$r=0$ & $34.322 * *$ & 33.877 & $76.223 * *$ & 69.819 \\
$r=1$ & 16.222 & 27.584 & 41.901 & 47.856 \\
$r=2$ & 14.259 & 21.132 & 25.679 & 29.797 \\
$r=3$ & 9.416 & 14.265 & 11.420 & 15.495 \\
\hline
\end{tabular}

Notes: $* *$ indicates significance at the $5 \%$ level; The $5 \%$ finite sample critical values are constructed from the asymptotic critical values from Osterwald-Lenum (1992) using the method of Cheung and Lai (1993). $r$ is the cointegration rank.

After normalizing the cointegration vector in relation to the $C A N$, the long-run relationship equation is illustrated as follows:

$$
\begin{aligned}
& C A N=-1.385 P E K+1.111 C K G+ \\
& 1.633 S Z X+0.120 T S N
\end{aligned}
$$

The house prices in $C A N$ are positively affected by those in $C K G, S Z X$, and $T S N$, but negatively influenced by those of PEK. This shows that expansive house prices in Chongqing, Shenzhen, and Tianjin lead to increasing house prices in Guangzhou. One possible explanation for this positive impact is the importance of business cycles. Davis and Heathcote (2005) demonstrate that residential investment leads the cycle, while non-residential investment lags the cycle in US housing market. Applying city-level housing prices data, Jud and Winkler (2002) indicate that real housing price increases are strongly affected by population growth and real changes in income, and interest rates. In our sample, Tianjin, Chongqing, and Shenzhen are respectively the most important economic engine in the northern, central, and southern region of China. When business cycles hit the economic centre areas, such as Chongqing, Shenzhen, and Tianjin, the regional house prices there change first and the housing price movements diffuse to Guangzhou.

On the other hand, a rising house prices in Beijing causes the house prices in Guangzhou to decrease. In the case of China, Liang and Cao (2007) find that credit policy has substantial impacts on house price movements in the eastern and western regions, while the economic conditions is more prominent factor in the central region. Beijing, as the most important economic center in China, has the largest income growth and population expansion and the most non-residential investment in real estate. A closer interaction of migrants makes the dwellings relatively close substitutes between housing market areas. Finally, as to the relative importance of regional house prices, the impacts of the ripple effect are particularly large in Shenzhen than those in other regions. A possible reason could be ascribed to its opened up for market reform, the personal income increased dramatically.

To examine whether the effect of each exogenous variable on the house prices in Beijing is significant, we perform the tests of Johansen and Juselius' (1990) approach on the values of the coefficients for the whole cointegrated vector model, as shown in Table 8. The results confirm that the effects of PEK, CKG, and SZX for Equation (6) are significant at the $10 \%$ level.

Table 8. Cointegration vector coefficient significance test

\begin{tabular}{lllll}
\hline & PEK & CKG & SZX & TSN \\
\hline Statistic & $5.002^{*}$ & $8.821^{* *}$ & $8.806^{* *}$ & 0.115 \\
p-value & {$[0.025]$} & {$[0.003]$} & {$[0.003]$} & {$[0.735]$} \\
\hline
\end{tabular}

Notes: The LR test statistic is obtained by means of the $x^{2}(r)$ test. Figures within brackets are the p-values. ${ }^{* *}$ and * denote significance at the $5 \%$ and $10 \%$ levels, respectively. 
Once the variables are cointegrated, an interesting issue may be raised, i.e., the possible directions of a causal relationship among these regional house prices. To this end, we now examine the existence of weak exogeneity by imposing some linear restrictions on the adjustment coefficients. If the null hypothesis of existing weak exogeneity cannot be rejected, this indicates that the variable is a weak exogenous variable. Given the existence of one cointegrating vector, the test statistics are asymptotically distributed as $\chi^{2}(1)$. Table 9 shows that weak exogeneity cannot be rejected for $P E K, C K G$, and $S Z X$, while it can be rejected for $C A N$ and $T S N$ at the $10 \%$ level, indicating a uni-directional causal relationship running from $P E K, C K G$, and $S Z X$ to $C A N$ and $T S N$. Therefore, in our empirical model PEK, $C K G$, and $S Z X$ are the "cause" of CAN and TSN. In other words, the house price shocks in Beijing, Chongqing and Shenzhen ripple out to Guangzhou and Tianjin. The result indicates that a change in housing prices in one region affects its neighbours' housing price. This is especially the case in the core cities such as Beijing and Shenzhen, where signals the trend for the entire market. Why can Beijing, Chongqing, and Shenzhen lead the house price of Guangzhou and Tianjin? In light of its geographical position, Guangzhou and Tianjin are not far away from the neighbouring areas of Shenzhen and Beijing. Through the influence of regional asset transfer or a spatial arbitrage diffusion process, the regional house price shocks spread to Guangzhou and Tianjin. Such phenomena are similar to the study of the British ripple effect, as house prices change first in London, and the South East and then diffuse to North West (Meen 1999). On the other hand, from the view point of business cycles, Chongqing, and Shenzhen are respectively the most important economic center in the central, and southern China. The price shocks spread to Guangzhou and Tianjin through the influence of spatial information diffusion process.

Table 9. Weak exogeneity test

\begin{tabular}{llllll}
\hline & CAN & PEK & CKG & SZX & TSN \\
\hline Statistic & $2.283^{*}$ & 0.440 & 2.287 & 1.281 & $10.164^{* *}$ \\
p-value & {$[0.009]$} & {$[0.507]$} & {$[0.130]$} & {$[0.258]$} & {$[0.001]$} \\
\hline
\end{tabular}

Notes: The LR test statistic is obtained by means of the $x^{2}(r)$ test. Figures in brackets are p-values. ** and * denote significance at the $5 \%$ and $10 \%$ levels, respectively.

\section{CONCLUSIONS}

This paper examines the ripple effect of China's regional house prices with monthly data covering the period from December 2000 to July 2013. A wide range of testing procedures is used to detect the stationarity properties, the long-run equilibrium, and the lead-lag relationship among regional house prices. Unlike the traditional panel unitroot tests, the advanced panel SURADF unit-root test of Breuer et al. $(2001,2002)$ seems to have more robustness and better power in detecting the presence of the unit-root hypothesis. Meanwhile, more complete information is made available by measuring the half-lives, which provide an analysis of short-run adjustments and the mean reversion process. Furthermore, we apply Johansen's multivariate cointegration tests to investigate the convergence among regional house prices based on I(1) series and then investigate the causal relationships by using the weak exogeneity test.

Our results of the Panel SURADF tests illustrate that the regional house prices in the sample cites consist of a mixture of $\mathrm{I}(0)$ and $\mathrm{I}(1)$ processes, that traditional ones tend to be misleading. The house prices of Beijing, Chongqing, Guangzhou, Shenzhen, and Tianjin are non-stationary, whereas the prices of Shanghai are trend-stationary. Several implications can be drawn from these results. First, the unit-root null hypothesis proffers knowledge on whether a shock has a permanent or a transitory effect on regional house prices. Over the time period for which the null is rejected, any economic policies are interpreted as having a transitory effect on prices. Second, from an empirical perspective, econometric modelling requires knowledge on the unit-root properties of prices data. When examining for cointegration or causality, a pre-requisite is that the variables used in the analysis contain a unit-root. If relevant econometric works lack a diagnostic analysis of the order of integration, then the subsequently conduct of cointegration analysis might be inappropriate.

The Johansen's multivariate cointegration tests results herein provide substantive evidence of a fairly strong long-run cointegration relationship among the five regions of Beijing, Chongqing, Guangzhou, Shenzhen, and Tianjin. A ripple effect exists within these regional house markets in China. This may ultimately be useful for predicting the long-run tendencies of Chinese regional housing market in the presence of macroeconomic shocks. From the results of the weak 
exogeneity test, Chinese house markets present an uni-directional causality from Beijing, Chongqing, and Shenzhen to Guangzhou and Tianjin, confirming the presence of the ripple effect from the other three regions to Guangzhou and Tianjin. This result is similar to the British cases, as house prices change first in London, the capital and most important economic centre, and the South East and then diffuse toward the North West.

In summary, our empirical analysis provides evidence of regional house price convergence and hence market integration that supports the price diffusion or ripple effect in the case of China. Meanwhile, more complete information is made available to the policy-maker. One policy implication that emerges is that the Chinese government should pay attention to housing price changes in the core cities. Government can use the changes of house prices of the dominating areas to predict the house prices in the outer regions and implement policies to maintain a stable relationship between regional house prices accordingly.

\section{ACKNOWLEDGEMENTS}

We would like to thank the Editor and the three anonymous referees for their highly constructive comments.

\section{REFERENCES}

Alexander, C.; Barrow, M. 1994. Seasonality and cointegration of regional house prices in the UK, Urban Studies 31: 1667-1689. http://dx.doi. org/10.1080/00420989420081571

Ashworth, J.; Parker, S. 1997. Modelling regional house prices in the UK, Scottish Journal of Political Economy 44: 225-246. http://dx.doi.org/10.1111/14679485.00055

Balcilar, M.; Beyene, A.; Gupta, R.; Seleteng, M. 2013. 'Ripple' effects in South African house prices, Urban Studies 50(5): 876-894. http://dx.doi. org/10.1177/0042098012458551

Breitung, J. 2000. The local power of some unit root tests for panel data, in B. Baltagi (Ed.). Nonstationary panels, panel cointegration, and dynamic panels: advances in econometrics 15: 161-178. Amsterdam: JAI.

Breuer, J. B.; McNown, R.; Wallace, M. S. 2001. Misleading inferences from panel unit-root tests with an illustration from purchasing power parity, Review of International Economics 9(3): 482-493. http://dx.doi. org/10.1111/1467-9396.00294

Breuer, J. B.; McNown, R.; Wallace, M. S. 2002. Seriesspecific unit root tests with panel data, Oxford Bulletin of Economics and Statistics 64(5): 527-546. http:// dx.doi.org/10.1111/1468-0084.00276
Canarella, G.; Miller, S. M.; Pollard, S. 2012. Unit roots and structural change: an application to US house price indices, Urban Studies 49(4): 757-776. http:// dx.doi.org/10.1177/0042098011404935

Chen, P. F.; Chien, M. S.; Lee, C. C. 2011. Dynamic modeling of regional house price diffusion in Taiwan, Journal of Housing Economics 20: 315-332. http://dx.doi.org/10.1016/j.jhe.2011.09.002

Cheung, Y.-W.; Lai, K. S. 1993. Finite-sample sizes of Johansen's likelihood ratio tests for cointegration, Oxford Bulletin of Economics and Statistics 55(3): 313-328. http://dx.doi.org/10.1111/j.1468-0084.1993. mp55003003.x

Chiang, S. H. 2014. Housing markets in China and policy implications: comovement or ripple effect, China \& World Economy 22(6): 103-120. http://dx.doi. org/10.1111/cwe.12094

Chien, M. S. 2010. Structural breaks and the convergence of regional house prices, Journal of Real Estate Finance and Economics 40(1): 77-88. http://dx.doi. org/10.1007/s11146-008-9138-y

Clapp, J. M.; Dolde, W.; Tirtiroglu, D. 1995. Imperfect information and investor inferences from housing price dynamics, Real Estate Economics 23: 239-269. http://dx.doi.org/10.1111/1540-6229.00665

Cook, S. 2003. The convergence of regional house prices in the UK, Urban Studies 40(11): 2285-2294. http://dx.doi.org/10.1080/0042098032000123295

Cook, S. 2005. Regional house price behaviour in the UK: application of a joint testing procedure, Physica A 345: 611-621. http://dx.doi.org/10.1016/S03784371(04)01051-9

Davis, M.; Heathcote, J. 2005. Housing and the business cycle, International Economic Review 46(3): 751-784. http://dx.doi.org/10.1111/j.1468-2354.2005.00345.x

Dickey, D.; Fuller, W. 1979. Distribution of the estimators for autoregressive time series with a unit root, Journal of the American Statistical Association 74: 427-431.

Dolde, W.; Tirtiroglu, D. 1997. Temporal and spatial information diffusion in real estate price changes and variances, Real Estate Economics 25: 539-565. http://dx.doi.org/10.1111/j.1468-2354.2005.00345.x

Drake, L. 1995. Testing for convergence between UK regional house prices, Regional Studies 29(4): 357-366. http://dx.doi.org/10.1080/00343409512331349023

Elliott, G.; Rothenberg, T. J.; Stock, J. H. 1996. Efficient tests for an autoregressive unit root, Econometrica 64: 813-836. http://dx.doi.org/10.2307/2171846

Engle, R. F.; Granger, C. W. J. 1987. Cointegration and error correction: representation, estimation and testing, Econometrica 55: 251-276. http://dx.doi. org/10.2307/1913236

Fraser, P.; Hoesli, M.; McAlevey, L. 2008. House prices and bubbles in New Zealand, Journal of Real Estate Finance and Economics 37(1): 71-91. http://dx.doi. org/10.1007/s11146-007-9060-8

Gallin, J. 2006. The long-run relationship between house prices and income: evidence from local housing markets, Real Estate Economics 34(3): 417-438. http://dx.doi.org/10.1111/j.1540-6229.2006.00172.x 
Guo, F.; Huang, Y. S. 2010. Does 'hot money' drive China's real estate and stock markets?, International Review of Economics and Finance 19(3): 452-466. http://dx.doi.org/10.1016/j.iref.2009.10.014

Gupta, R.; Miller, S. M. 2012. The time-series properties of house prices: a case study of the southern California market, Journal of Real Estate Finance and Economics 44(3): 339-361. http://dx.doi.org/10.1007/ s11146-010-9234-7

Hadri, K. 2000. Testing for stationarity in heterogeneous panel data, Econometrics Journal 3(2): 148-161. http://dx.doi.org/10.1111/1368-423X.00043

Holmes, M. 2007. How convergent are regional house prices in the United Kingdom? Some new evidence from panel data unit root testing, Journal of Economic and Social Research 9: 1-17.

Holmes, M. J.; Grimes, A. 2008. Is there long-run convergence among regional house prices in the UK?, Urban Studies 45(8): 1531-1544. http://dx.doi. org/10.1177/0042098008091489

Huang, F.-x.; Li, C.; Li, Y. 2010a. Ripple effect of housing prices among Chinese deputy provincial cities based on an alternative approach, International Journal of Business Administration 1: 19-24. http://dx.doi.org/10.5430/ijba.v1n1p19

Huang, F.-x.; Zhou, Y.; Li, C. 2010b. Ripple effect of housing prices fluctuations among nine cities of China, Management Science and Engineering 4: 41-54.

Hui, E. C. M.; Yue, S. 2006. Housing price bubbles in Hong Kong, Beijing and Shanghai: a comparative study, Journal of Real Estate Finance and Economics 33(4): 299-327. http://dx.doi.org/10.1007/s11146006-0335-2

Im, K. S.; Pesaran, M. H.; Shin, Y. 2003. Testing for unit roots in heterogeneous panels, Journal of Econometrics 115: 53-74. http://dx.doi.org/10.1016/S03044076(03)00092-7

Johansen, S. 1988. Statistical analysis of cointegration vectors, Journal of Economic Dynamics and Control 12(2/3): 231-254. http://dx.doi.org/10.1016/01651889(88)90041-3

Johansen, S.; Juselius, K. 1990. Maximum likelihood estimation and inference on cointegration: with applications to the demand for money, Oxford Bulletin of Economics and Statistics 52(2): 169-210. http:// dx.doi.org/10.1111/j.1468-0084.1990.mp52002003.x

Jud, G. D.; Winkler, D. T. 2002. The dynamics of metropolitan housing prices, Journal of Real Estate Research 23: 29-45.

Kuethe, T. H.; Pede, V. O. 2011. Regional housing price cycles: A spatio-temporal analysis using US statelevel data, Regional Studies 45(5): 563-574. http://dx.doi.org/10.1080/00343400903497897

Kwiatkowski, D.; Phillips, P.; Schmidt, P.; Shin, J. 1992. Testing the null hypothesis of stationarity against the alternative of a unit root, Journal of Econometrics 54: 159-178. http://dx.doi.org/10.1016/03044076(92)90104-Y

Lean, H. H.; Smyth, R. 2013. Regional house prices and the ripple effect in Malaysia, Urban Studies 50(5): 895922. http://dx.doi.org/10.1177/0042098012459582
Lean, H. H.; Smyth, R. 2014. Dynamic interaction between house prices and stock prices in Malaysia, International Journal of Strategic Property Management 18(2): 163-177. http://dx.doi.org/10.3846/16487 15X.2014.925006

Lee, C. C.; Chien, M. S. 2011. Empirical modeling of regional house prices and the ripple effect, $U r$ ban Studies 48(10): 2029-2047. http://dx.doi. org/10.1177/0042098010385257

Lee, C. C.; Lee, C. C.; Chiu, Y. B. 2013. The link between life insurance activities and economic growth: some new evidence, Journal of International Money and Finance 32: 405-427. http://dx.doi.org/10.1016/j. jimonfin.2012.05.001

Lee, J.; Strazicich, M. C. 2003. Minimum Lagrange multiplier unit root test with two structural breaks, Review of Economics and Statistics 85: 1082-1089. http://dx.doi.org/10.1162/003465303772815961

Levin, A.; Lin, C. F.; Chu, C. S. 2002. Unit root tests in panel data: asymptotic and finite-sample properties, Journal of Econometrics 108: 1-24. http://dx.doi. org/10.1016/S0304-4076(01)00098-7

Liang, Q.; Cao, H. 2007. Property prices and bank lending in China, Journal of Asian Economics 18(1): 63-75. http://dx.doi.org/10.1016/j.asieco.2006.12.013

Liao, W. C.; Zhao, D.; Lim, L. P. 2015. Foreign liquidity to real estate market: ripple effect and housing price dynamics, Urban Studies 52: 138-158. http://dx.doi. org/10.1177/0042098014523687

Liu, J.; Wu, S.; Zidek, J. V. 1997. On segmented multivariate regressions, Statistica Sinica 7: 497-525.

Ljung, G. M.; Box, G. E. P. 1978. On a measure of lack of fit in time series models, Biometrika 65(2): 297-303. http://dx.doi.org/10.1093/biomet/65.2.297

MacDonald, R.; Taylor, M. 1993. Regional house prices in Britain: long-run relationships and short-run dynamics, Scottish Journal of Political Economy 40: 43-55. http://dx.doi.org/10.1111/j.1467-9485.1993.tb00636.x

Maddala, G. S.; Wu, S. 1999. A comparative study of unit root tests with panel data and a new simple test, $O x$ ford Bulletin of Economics and Statistics 61: 631-652. http://dx.doi.org/10.1111/1468-0084.61.s1.13

Malpezzi, S. 1999. A simple error-correction model of housing prices, Journal of Housing Economics 8: 27-62. http://dx.doi.org/10.1006/jhec.1999.0240

Meen, G. 1996. Spatial aggregation, spatial dependence and predictability in the UK housing market, Housing Studies 11(3): 345-372. http://dx.doi. org/10.1080/02673039608720862

Meen, G. 1999. Regional house prices and the ripple effect: a new interpretation, Housing Studies 14: 733-753. http://dx.doi.org/10.1080/02673039982524

Narayan, P. K.; Smyth, R. 2007. Mean reversion versus random walk in G7 stock prices evidence from multiple trend break unit root tests, Journal of International Financial Markets, Institutions \& Money 17: 152-166. http://dx.doi.org/10.1016/j.intfin.2005.10.002

Newey, W. K.; West, K. D. 1994. Automatic lag selection in covariance matrix estimation, Review of Economic Studies 61: 631-653. http://dx.doi. org/10.2307/2297912 
Ng, S.; Perron, P. 2001. Lag length selection and the construction of unit root tests with good size and power, Econometrica 69(6): 1519-1554. http://dx.doi. org/10.1111/1468-0262.00256

Osterwald-Lenum, M. 1992. A note with quantiles of the asymptotic distribution of the maximum likelihood cointegration rank test statistics, Oxford Bulletin of Economics and Statistics 54(3): 461-472. http://dx.doi.org/10.1111/j.1468-0084.1992.tb00013.x

Phillips, P. C. B.; Perron, P. 1988. Testing for a unit root in time series regression, Biometrika 75: 335-346. http://dx.doi.org/10.1093/biomet/75.2.335

Reilly, B.; Witt, R. 1994. Regional house prices and possessions in England and Wales: an empirical analysis, Regional Studies 28(5): 475-482. http://dx.doi.or g/10.1080/00343409412331348406

Rossi, B. 2005. Confidence intervals for half-life deviations from purchasing power parity, Journal of
Business and Economic Statistics 23(4): 432-442. http://dx.doi.org/10.1198/073500105000000027

Shi, S.; Young, M.; Hargreaves, B. 2009. The ripple effect of local house price movements in New Zealand, Journal of Property Research 26(1): 1-24. http://dx.doi.org/10.1080/09599910903289880

Wu, J.; Gyourko, J.; Deng, Y. 2012. Evaluating conditions in major Chinese housing markets, Regional Science and Urban Economics 42(3): 531-543. http://dx.doi.org/10.1016/j.regsciurbeco.2011.03.003

Yang, J.; Liu, H.; Leatham, D. J. 2013. The multi-market analysis of a housing price transmission model, Applied Economics 45: 3810-3819. http://dx.doi.org/ 10.1080/00036846.2012.734595

Zhang, F.; Morley, B. 2014. The convergence of regional house prices in China, Applied Economics Letters 21(3): 205-208. http://dx.doi.org/10.1080/13504851. 2013.848021 